\title{
Renal Cell Carcinoma presented with An Intramedullary Spinal Cord Metastasis : A Case Report
}

\author{
Md. Rashedul Islam¹, Tanbin Rahman², Rumana Habib ${ }^{3}$, Aminur Rahman ${ }^{4}$, Nirmalendu Bikash Bhowmik ${ }^{5}$,
} Md. Amirul Haque ${ }^{6}$

\begin{abstract}
:
Intramedullary spinal cord metastasis is one of the rare manifestations of systemic neoplasm causing diagnostic dilemma. Here we report a case of metastatic renal cell carcinoma presented initially as spinal cord lesion. A 62 years old Bangladeshi gentleman presented with spastic paraparesis, bone pain with unexplained weight loss. After thorough examination \& detailed investigations we found intramedullary spinal cord metastasis with infiltrative lesion on bone scan. We confirmed renal cell carcinoma after doing CT Abdomen and histopathology as primary site of lesion. He was treated by radical nephrectomy \& radiotherapy. It is imperative that clinicians should be cautious of occult carcinoma as the cause of suspicious intramedullary spinal cord lesion.
\end{abstract}

Keywords: Intramedullary spinal cord lesion, Renal cell carcinoma.

\section{Introduction :}

Although metastatic neoplasms of the spine are common, pure intramedullary spinal cord metastasis (ISCM) is a rare manifestation of systemic cancer, which indicates the occurrence of remote dissemination, and thus, the terminal phase of cancer ${ }^{1,2,3}$. The most common primary tumors of ISCM are from the lung, breast and melanoma, which account for about three-fourth, but lymphoma, kidney, colon and thyroid are uncommon ${ }^{4,5,6}$. Despite its rarity, intramedullary metastasis should be considered in patients with systemic malignancy presenting with myelopathic symptoms ${ }^{7}$. The recognition of intrameullary spinal cord metastasis is an ominous finding as it generally occurs in the setting of widespread systemic and intracranial disease and is the prelude to cancer death by a few months ${ }^{8}$. The presenting

1. Dr. Md. Rashedul Islam, MBBS, MRCP (UK), FCPS (Medicine), FACP (USA), Registrar, Department of Neurology, BIRDEM General Hospital

2. Dr. Tanbin Rahman, MBBS, MD (Hematology) Student, Dhaka Medical College \& Hospital

3. Dr. Rumana Habib, MBBS, FCPS (Medicine), Assistant Professor, Department of Neurology, BIRDEM General Hospital

4. Dr. Aminur Rahman, MD, FACP (USA), MBBS, Consultant, Department of Neurology, BIRDEM General Hospital

5. Dr. Nirmalendu Bikash Bhowmik, MBBS, MD, Professor, Department of Neurology, BIRDEM General Hospital

6. Prof. Dr. Md. Amirul Haque, MBBS, FCPS, DCN (London), FACP (USA), FRCP (Glasgow), Professor \& Head, Department of Neurology, BIRDEM General Hospital

Corresponding Author :

Dr. Md. Rashedul Islam

MBBS, MRCP (UK), FCPS (Medicine), FACP(USA)

Registrar, Department of Neurology

BIRDEM General Hospital

Dhaka 1000, Bangladesh

Email: rashed2k2001@yahoo.com symptoms of ISCM vary from pain, sensory loss, weakness, urinary incontinence to pseudo Brown-Sequard and/or Brown-Sequard syndrome ${ }^{9}$. The duration of symptoms before diagnosis of ISCM ranges from days to a few months ${ }^{9,10}$. The very rare occurrence of ISCM and the absence of pathognomic symptoms often lead to an undue delay until the underlying malignancy is discovered ${ }^{10}$. Surgery and radiotherapy have been recommended controversially in the treatment of ISCM. Although long-term survival is poor, treatment may preserve ambulation in the case of early diagnosis; it may also stabilize neurological function and this may change the patient's health related quality of life unbelievably ${ }^{9,11,12}$. Careful history $\&$ thorough examination may lead to early diagnosis which can halt neurological deficits \& effective palliation can be offered to the patient.

\section{Case report :}

A 62-years-old man presented with 1month history of progressive unremitting back pain, exacerbated at night \& walking, associated with perianal parestheisa \& urinary incontinence. He also had rapidly progressing paraparesis without any radicular pain. On examination, his motor power of both hip flexion was $2 / 5$ and other distal lower extremity was $3 / 5$ along with hypertonia, hyperreflexia, bilateral extensor plantar with sensory level at the level of T12. He had undergone series of investigations including neuroimaging, CSF analysis, routine blood tests. MRI of dorsal-lumbar spine revealed hypointense thickening of spinal cord extending from the T4 to L1 spine on T1WI, patchy enhancement on contrast T1WI \& hyperintense on T2WI suggesting spinal cord edema. An intramedullary ovoid lesion with thick rim enhancement \& intalesional hyperintense area on T2W1 was seen at the level of T12 spine (Figure 1). No infectious etiology had been found despite performing investigation. The tissue biopsy of the involved area was not obtained as he had not consented to it. On further query, he complained unexplained weight loss of $5 \mathrm{~kg}$ in the last 2 months. We went for evaluation of unexplained weight loss \& found raised ESR, normal chest X-ray. Enlarged, distorted right renal mass 
was revealed on ultrasonography. CT scan of abdomen revealed heterogeneously enhancing soft tissue mass involving right kidney suggestive of right renal mass with focal calyectasis(Figure 2). CT guided FNAC confirmed the diagnosis renal cell carcinoma. Radical nephrectomy was done afterwards and the histology confirmed renal cell carcinoma, conventional type. Early Postoperative period was uneventful. He complained of severe pain around left scapula afterwards which was constant, exacerbated by movement of shoulder, unremitting with pain killers along with intractable back pain. X ray of the left shoulder along with spine was unremarkable. Whole bone scintigraphy revealed increased uptake of radiotracer L5 vertebra \& inferior aspect of left scapula suggestive of infiltrative bone lesion (Figure 3). He also had hypercalcemia probably due to paraneoplastic effect of the tumour producing PTHrP, and bony metastases as the PTH assay was undetectable. He received appropriate treatment for his hypercalcemia. Finally we diagnosed the case as renal cell carcinoma with intramedullary spinal cord metastasis with bone metastasis. Neurosurgical consultation was taken \& patient refused surgery. Focal radiotherapy on the spine was initiated due to his refusal for surgery. Over the following 10 days during radiotherapy, his neurological deficit progressed to $4 / 5$ on the right lower extremity and $4 / 5$ on the left lower extremity. There was no significant improvement of modalities of sensation with mild painful paresthesia on both lower extremities. He was able to walk with the support of walking aid after 1 month.

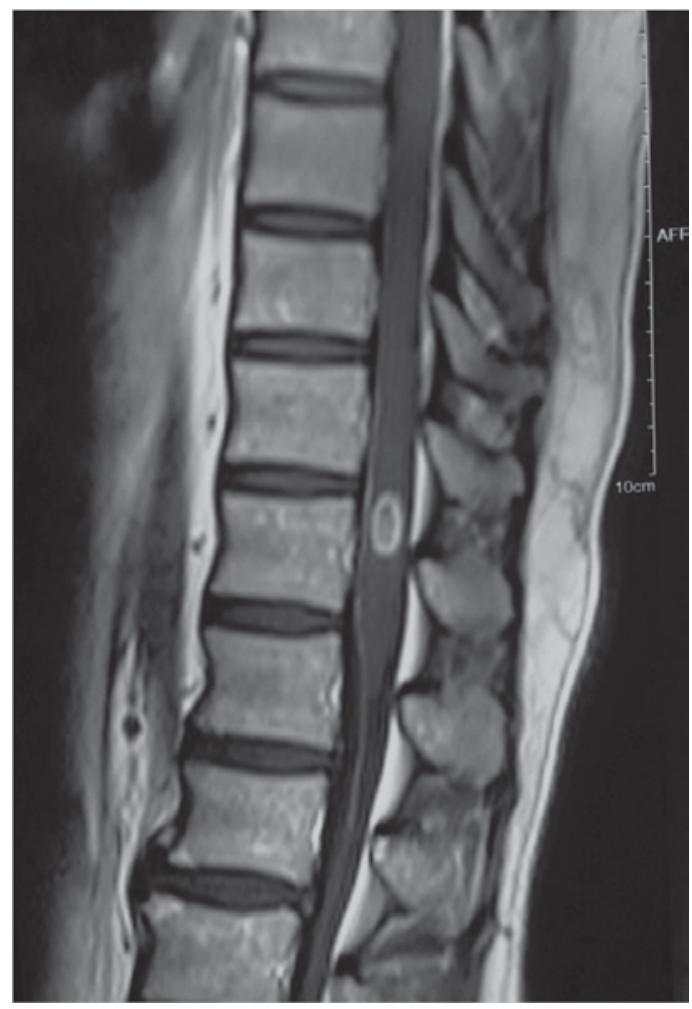

Fig 1: MRI of dorsal-lumbar spine showing an intramedullary ovoid lesion with thick rim enhancement \& intalesional hyperintense area on T2W1 at the level of T12 vertebrae.

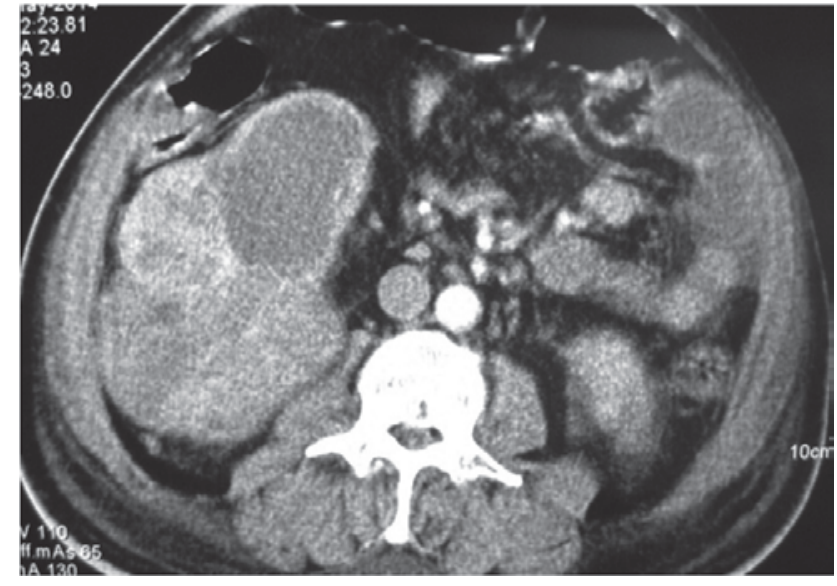

Fig 2: CT scan of abdomen showing heterogeneously enhancing soft tissue mass involving right kidney suggestive of right renal mass with focal calyectasis.

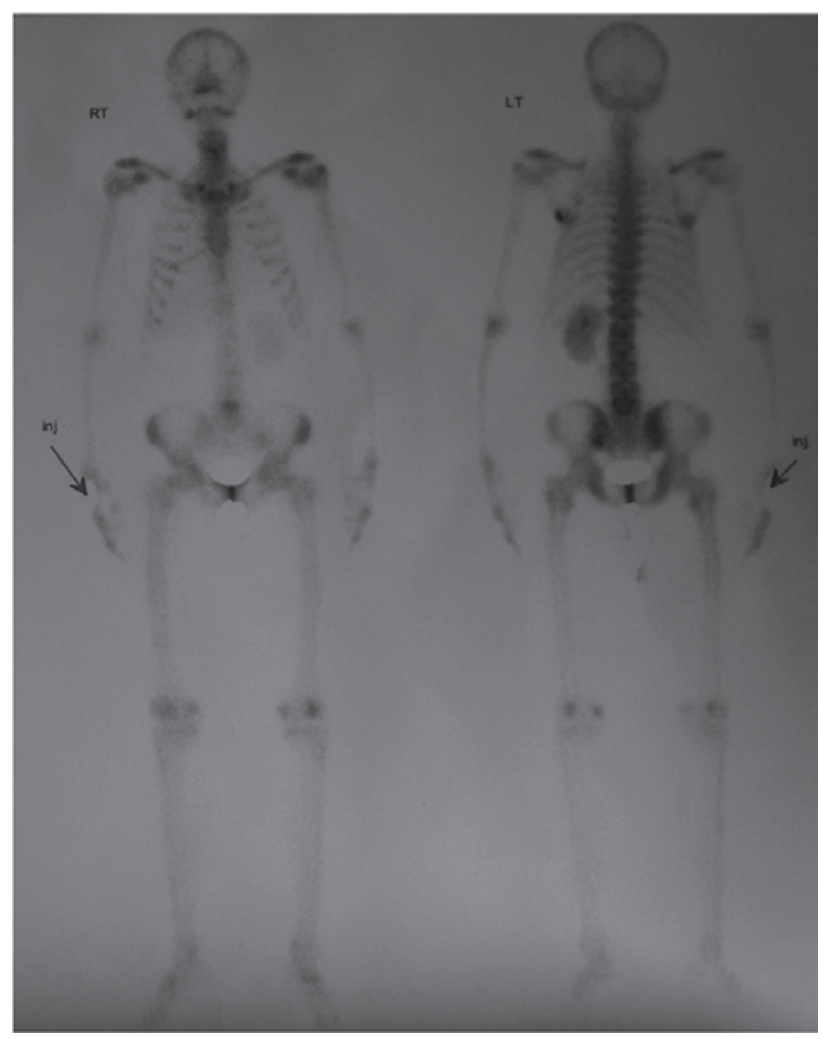

Fig 3: Whole bone scintigraphy revealed increased uptake of radiotracer L5 vertebra \& inferior aspect of left scapula suggestive of infiltrative bone lesion.

\section{Discussion :}

Spinal metastases may be seen in as much as $70 \%$ of patients with systemic neoplasia. Among these lesions, intramedullary spinal metastases are rare, comprising only $0.5 \%$ of spinal axis metastases. Majority of them arise from the lung neoplasia,with small cell carcinoma being the Predominant 
histological subtype. Breast, colorectal, renal, melanoma, thyroid and lymphoma have all infrequently been reported to be the origin ${ }^{13}$. However, metastasis to the intramedullary spinal cord is extremely rare as the initial sign of a disseminated carcinoma ${ }^{14}$. There are several hypotheses to explain how to metastasize into the spinal cord parenchyma. Kalayci et al. ${ }^{6}$ reviewed articles and summarized them into 3 pathologic mechanisms.

First, haematogeneous spread via the artery or vertebral venous plexus (Batson's venous plexus) is believed to account for most cases. Second, tumor cells originated from carcinomatous meningitis infiltrate into the Virchow-Robin spaces of the vessels, penetrate the pial membrane and invade the spinal cord parenchyma. The third mechanism is direct invasion from contiguous structures. In our case, considering the high incidence of anastomosis between the left renal vein and the vertebral venous plexus, hematogenous spread can be a reasonable mechanism ${ }^{15}$. In patients without history of systemic neoplasia such as the patient in our report, a detailed clinical history and physical examination coupled with selected laboratory and diagnostic imaging investigations may delineate primary or secondary spinal malignant lesions from other more benign differential diagnostic entities. MRI is useful in determining the extent of CNS involvement which may affect the therapeutic decision making in many patients ${ }^{13,16}$. Treatment modalities for ISCM include radiotherapy, surgery, and chemotherapy. The modality of treatment should be decided by clinical and neurological status. Focal radiotherapy has been accepted for an effective treatment modality for ISCM with arresting tumor growth and preventing further neurological deficit ${ }^{8}$. However, the efficacy of radiotherapy may be limited to radio-sensitive tumors, such as small cell lung cancer, breast cancer, and lymphoma. These radio-sensitive tumors are most frequently found as the origin of ISCM ${ }^{4,5,6}$. Previous reports favoring radiation therapy are somewhat biased as their clinical elements mainly consist of these radio-sensitive tumors. Despite the radio-resistance of RCC itself, focal radiotherapy has been preferred for the first-line treatment modality of ISCM from RCC due to the absence of effective systemic therapy for metastatic RCC and short life expectancy which estimated at 3 to 9 months ${ }^{17}$. The prognosis of a patient who has an intramedullary cord lesion is grave. Spine surgeons are playing greater role in the management of patients with metastatic disease. With the advent of new surgical strategies many patients may benefit from effective treatment modalities ranging from radical, open excision through minimally invasive surgery such as endoscopy to ultraminimal/ noninvasive spinal radiosurgery. Making an early diagnosis of ISCM is useful in planning either early or no major intervention. Providing patients with successful palliation and improving their quality of life demand multidisciplinary strategic treatment planning ${ }^{13,18}$.

\section{Conclusion :}

This report presents an extremely unusual presentation of metastatic renal cell carcinoma as intramedullary spinal cord lesion. Careful history \& thorough examination can lead to early diagnosis and management of such cases which can reduce the neurological deficits \& ensure better functional outcome.

\section{References :}

1. Edelson RN, Deck MD, Posner JB. Intramedullary spinal cord metastases: clinical and radiographic findings in nine cases. Neurology 1972; 22: 1222-31.

2. Jellinger $\mathrm{K}$, Kothbauer $\mathrm{P}$, Sunder-Plassmann E, Weiss R. Intramedullary spinal cord metastases. J Neurol 1979; 220: 31-41.

3. Grem JL, Burgess J, Trump DL. Clinical features and natural history of intramedullary spinal cord metastasis. Cancer 1985; 56 : 2305-14.

4. Moffie D, Stefanko SZ. Intramedullary metastasis. Clin Neurol Neurosurg 1980; 82: 199-202.

5. Connolly ES Jr, Winfree CJ, McCormick PC, Cruz M, Stein BM. Intramedullary spinal cord metastasis: report of three cases and review of the literature. Surg Neurol 1996; 46: 329-37.

6. Kalayci M, Cağavi $\mathrm{F}$, Gül $\mathrm{S}$, Yenidünya $\mathrm{S}$, Açikgöz $\mathrm{B}$. Intramedullary spinal cord metastases: diagnosis and treatment - an illustrated review. Acta Neurochir (Wien) 2004; 146: 1347-54.

7. Mut M, Schiff D, Shaffrey ME: Metastasis to nervous system: spinal epidural and intramedullary metastases. J Neurooncol 2005, 75:43-56.

8. Grem JL, Burgess J, Trump DL: Clinical features and natural history of intramedullary spinal cord metastasis. Cancer 1985, 56:2305-2014.

9. Schiff D, O’Neill BP: Intramedullary spinal cord metastases: clinical features and treatment outcome. Neurology 1996, 47:906-912.

10. Lee SS, Kim MK, Sym SJ, Kim SW, Kim WK, Kim SB, Ahn JH: Intramedullary spinal cord metastases: a single-institution experience. J Neurooncol 2007, 84:85-89.

11. Marquart C, Weckesser M, Schueller P, Hasselblat M, Wassmann $\mathrm{H}$, SchrÖder J: Intramedullary spinal cord metastasis as initial presentation of systemic cancer-report of a rare case. Zentralbl Neurochir 2007, 68:214-216.

12. Fakih M, Schiff D, Erlich R, Loqan TF: Intramedullary spinal cord metastasis (ISCM) in renal cell carcinoma: a series of six cases. Ann Oncol 2001, 12:1173-1177.

13. Jacobs WB, Perrin RG: Evaluation and treatment of spinal metastases: an overview. Neurosurg Focus 2001, 11:e10.

14. Donovan DJ, Freeman JH: Solitary intramedullary spinal cord tumor presenting as the initial manifestation of metastatic renal cell carcinoma: case report. Spine 2006, 31:E460-E463.

15. Mosnier H, Calmat A, Leguerrier A, Cabrol C. Study of anastomoses between the left renal vein and the internal vertebral plexus. Bull Assoc Anat (Nancy) 1977; 61: 237-41.

16. Post MJ, Quencer RM, Green BA, Montalvo BM, Tobias JA, Sowers JJ, Levin IH: Intramedullary spinal cord metastases, mainly of nonneurogenic origin. AJR Am J Roentgenol 1987, 148:1015-1022.

17. Dunne JW, Harper CG, Pamphlett R. Intramedullary spinal cord metastases: a clinical and pathological study of nine cases. Q J Med 1986; 61: 1003-20.

18. Klimo P Jr, Schmidt MH: Surgical management of spinal metastases. Oncologist 2004, 9:188-196. 